\title{
Surgical Resection of Colorectal Cancer With Distant Metastases to Other than Liver or Lung
}

\author{
ATSUSHI NAITO ${ }^{1,2}$, YOSHINORI KAGAWA ${ }^{1}$, KENJI KAWAI ${ }^{1}$, ATSUSHI TAKENO ${ }^{1}$, \\ YUTAKA TAKEDA ${ }^{1}$, MASAHISA OHTSUKA ${ }^{2}$, YOZO SUZUKI ${ }^{2}$, MITSUNOBU IMASATO $^{2}$, \\ YUJIRO FUJIE ${ }^{2}$, HIROYUKI NAKABA ${ }^{2}$, HIROKI AKAMATSU ${ }^{2}$ and KOHEI MURATA ${ }^{1}$ \\ ${ }^{1}$ Department of Gastroenterological Surgery, Kansai Rosai Hospital, Amagasaki, Japan; \\ ${ }^{2}$ Department of Gastroenterological Surgery, Osaka Police Hospital, Osaka, Japan
}

\begin{abstract}
Background/Aim: If both distant metastases and the primary tumour of colorectal cancer $(C R C)$ are resectable, resection of the distant metastases is considered. The aim of this retrospective study was to determine the efficacy of curative resection of both primary and metastatic lesions in organs other than liver or lung in CRC patients. Patients and Methods: The medical records of 23 CRC patients who received $R O$ resection for primary and metastatic regions between 2009 and 2018 were retrospectively analyzed. Results: The 3-year overall survival (OS) in all 23 cases was $80.0 \%$. There was no clinicopathological factor associated with $O S$ on univariate analysis. Conclusion: Curative surgical resection appears to be useful for distant CRC metastases to organs other than liver or lung.
\end{abstract}

Colorectal cancer (CRC) is one of the most common malignancies in Japan. Of the patients who undergo curative resection of the primary tumour, nearly one third will develop recurrent disease. In addition, patients with stage IV CRC have a very poor prognosis, with the 5-year survival approaching $20 \%$ (1). However, if both the distant metastases and the primary tumour of CRC are resectable, curative resection of the primary tumour is performed, and resection of the distant metastases is considered to improve the prognosis (1). In particular, the 5-year overall survival (OS) rates after curative resection of hepatic or pulmonary metastases are well known to be $35-68 \%$ (2). Regarding other than hepatic or pulmonary metastases, there are only a

This article is freely accessible online.

Correspondence to: Atsushi Naito, MD, Ph.D., Department of Gastroenterological Surgery, Osaka Police Hospital, 10-31 Kitayamacho, Tennouji-ku, Osaka City, Osaka 543-0035, Japan. Tel: +81 667716051, Fax: +81667752838, e-mail: naito.atsu@gmail.com

Key Words: Colorectal cancer, metastases, R0 resection. few reports of resection of peritoneal metastases, and almost no reports of other organs. The aim of this retrospective study was to determine the efficacy of curative resection of both primary and metastatic lesions in tissues other than liver or lung in CRC patients.

\section{Patients and Methods}

A total of 23 patients with CRC with distant metastases in organs other than liver and lung underwent R0 resection of the primary and metastatic tumours at the Kansai Rosai Hospital from 2009 to 2018. The patients were Stage IV or had distant metastatic recurrence after curative surgery for Stage I-III.

Information on various clinicopathological factors of patients, including age, sex, tumour location, histological type, tumour markers, and status of distant metastatic organs was obtained from medical records and retrospectively analysed. Histological type was categorized as either differentiated (dif, well or moderately differentiated tubular adenocarcinoma) or undifferentiated (undif, mucinous or poorly differentiated adenocarcinoma). Regarding tumour location, those arising from the cecum and the ascending and transverse colon were defined as right-sided tumours, whereas those arising from the descending colon to the rectum were defined as left-sided tumours.

This study was reviewed and approved by the institutional review boards of the participating institutions (Approval number; 20160425).

Statistical analysis. The Kaplan-Meier method was used to generate actuarial survival estimates; these were compared using the log-rank test. All statistical analyses were performed using JMP version 14.0 (SAS Institute, Cary, NC, USA).

\section{Results}

The clinicopathological characteristics of all patients $(n=23)$ are presented in Table I. Their median age was 66 years (range=34-87 years). Synchronous resection for Stage IV was performed in 11 cases, and resection of metastatic recurrence after curative surgery was performed in 12 cases. All patients underwent R0 resection. The regimens of chemotherapy before resection of metastases were: CAPOX 
Table I. Clinicopathological characteristics of the patients.

\begin{tabular}{|c|c|c|}
\hline & $\begin{array}{l}\text { All patients } \\
\quad(\mathrm{n}=23)\end{array}$ & $(\%)$ \\
\hline \multicolumn{3}{|l|}{ Age (y) } \\
\hline Median (range) & 66 & $34-87$ \\
\hline$\geq 65$ & 10 & 43.5 \\
\hline$<65$ & 13 & 56.5 \\
\hline \multicolumn{3}{|l|}{ Gender } \\
\hline Male & 8 & 34.8 \\
\hline Female & 15 & 65.2 \\
\hline \multicolumn{3}{|l|}{ Tumour location } \\
\hline Right-sided colon $(\mathrm{C} / \mathrm{A} / \mathrm{T})$ & $5(2 / 3 / 0)$ & 21.7 \\
\hline Left-sided colon (D/S/R) & $18(\mathrm{D} / \mathrm{S} / \mathrm{R})$ & 78.3 \\
\hline \multicolumn{3}{|l|}{ Target } \\
\hline Stage IV & 11 & 47.8 \\
\hline Metastatic recurrence & 12 & 52.2 \\
\hline \multicolumn{3}{|l|}{ Histological type } \\
\hline Dif & 19 & 82.6 \\
\hline Undif & 4 & 17.4 \\
\hline \multicolumn{3}{|l|}{ CEA } \\
\hline Positive & 15 & 65.2 \\
\hline Negative & 8 & 34.8 \\
\hline \multicolumn{3}{|l|}{ CA19-9 } \\
\hline Positive & 4 & 17.4 \\
\hline Negative & 19 & 82.6 \\
\hline \multicolumn{3}{|l|}{ M status } \\
\hline M1a/M1b & $11(10 / 1)$ & 47.8 \\
\hline M1c & 12 & 52.2 \\
\hline \multicolumn{3}{|c|}{ Chemotherapy before metastasectomy } \\
\hline Yes & 7 & 30.4 \\
\hline No & 16 & 69.6 \\
\hline
\end{tabular}

Dif: Well or moderately differentiated tubular adenocarcinoma; Undif: mucinous or poorly differentiated adenocarcinoma; CEA positive: $>5.0 \mathrm{ng} / \mathrm{ml}$, negative: $\leq 5.0 \mathrm{ng} / \mathrm{ml}$; CA19-9 positive: $>37 \mathrm{U} / \mathrm{ml}$, negative: $\leq 37 \mathrm{U} / \mathrm{ml}$.

(capecitabine + oxaliplatin) + B-mab (bevacizumab), 2 cases; FOLFOXILI (5-FU + oxaliplatin + irinotecan) + B-mab; mFOLFOX6 (5-FU + oxaliplatin) + Bmab; capecitabine + Bmab; CAPOX; and capecitabine.

Table II shows the details of the metastatic sites in all 23 patients. The most common metastatic site was the ovary (7 cases, $30.4 \%$ ), followed by the peritoneum (6 cases, $26.1 \%$ ).

The median length of follow-up for all patients was 32 months (range $=10-73$ months). The 3 -year OS in all 23 cases was $80.0 \%$ (Figure 1). There was no clinicopathological factor associated with OS on univariate analysis (Table III).

\section{Discussion}

In this study, the prognosis of R0-resected CRC patients with distant metastases in organs other than liver or lung was evaluated. The 3-year OS in all 23 cases was $80.0 \%$. In a multi-institutional study in Japan, it was reported that the 3year OS after hepatectomy for liver metastases of CRC in
Table II. Metastatic sites.

\begin{tabular}{lcr}
\hline Metastatic sites & $\begin{array}{c}\text { All patients } \\
(\mathrm{n}=23)\end{array}$ & $(\%)$ \\
\hline Ovary & 5 & 21.7 \\
Extra-regional lymph node & 3 & 13.0 \\
Colon & 1 & 4.3 \\
Spleen & 1 & 4.3 \\
Liver+adrenal gland & 1 & 4.3 \\
P1 & 6 & 26.1 \\
P1+ovary & 1 & 4.3 \\
P2 & 1 & 4.3 \\
P2+ovary & 1 & 4.3 \\
P2+uterus & 2 & 8.7 \\
P3 & 1 & 4.3 \\
\hline
\end{tabular}

P1: metastases only to adjacent peritoneum; P2: a few metastases to distant peritoneum; P3: numerous metastases to distant peritoneum.

763 cases was $52.8 \%$ (3). The present results compare favourably with this report, suggesting that surgical resection is useful for distant metastases of CRC in tissues other than liver or lung. Another study has reported that patients with R0 resection $(n=26)$ had significantly better survival than those with palliative resection $(n=100)(5$-year OS: R0 resection $v s$. palliative resection $=55.6 \%$ vs. $9.2 \%, p<0.001$ ) (4). However, in that study, the number of patients with metastases in organs other than liver or lung was 50, and the number of $\mathrm{R} 0$ resections was not mentioned.

The most common metastatic site in the present study was ovary. It has been reported that isolated ovarian metastases from CRC are rare, representing only 3-8\% of metastases (5). Metastasectomy of the ovary is reported to confer a good survival rate $(6,7)$. However, since the 5-year OS rate after metastasectomy of the ovary in those reports was only 15$25 \%$, metastasectomy of the ovary has not been established.

The second most common metastatic site in this study was peritoneum. One report has shown that the 3-year OS rate $(n=78)$ was $45 \%$, and the 5-year OS rate was $28.7 \%$ after R0 resection of peritoneal metastasis (8). The Japanese Society for Cancer of the Colon and Rectum (JSCCR) guideline describes complete resection as desirable for P1 (metastases only to adjacent peritoneum), complete resection is considered for P2 (a few metastases to distant peritoneum) when easily resectable, and the efficacy of resection of $\mathrm{P} 3$ (numerous metastases to distant peritoneum) has not been demonstrated (1). Excision for resectable P seems to be recommended.

Finally, clinicopathological factors relating to a poor prognosis were unclear in the present study. Other groups have analysed prognostic factors in patients with stage IV $\mathrm{CRC}$, and they demonstrated that high pT stage and presence of positive node(s) were significant negative prognostic factors $(9,10)$. A prognostic factor in $\mathrm{R} 0$ resection for 


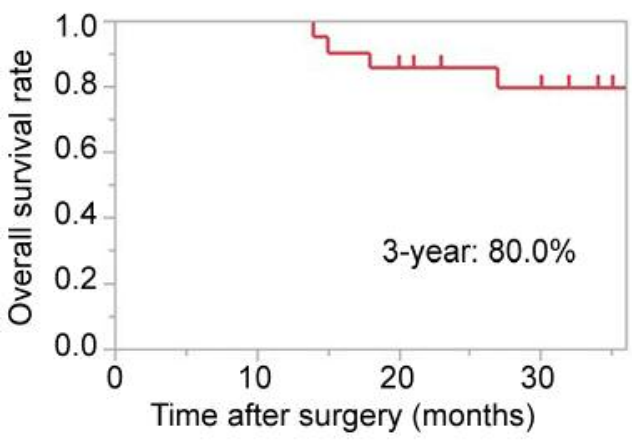

$(n=23)$

Figure 1. Three-year overall survival of the 23 patients.

metastatic CRC patients has not been reported, and no clinicopathological factor associated with OS was identified in the present study.

The main therapy of metastatic CRC at the present time is chemotherapy, but even triplet chemotherapy plus bevacizumab has a 3 -year OS of about $40 \%$ (11). The present data showed better OS with resection than with chemotherapy alone; thus, R0 resection may extend overall OS, even if recurrence occurs later. We believe that R0 resection also improves the prognosis for metastatic CRC to organs other than liver or lung.

Although advances in chemotherapy have prolonged survival of patients with metastatic colorectal cancer, the combination of R0 metastasectomy and chemotherapy may lead to better outcomes.

This study has certain limitations, such as low patient number, short observation period, and the fact that it was a retrospective, single-institute study. Thus, further large and multi-institutional studies are needed to confirm these findings.

\section{Conflicts of Interest}

The Authors have no conflicts of interest to declare regarding this study.

\section{Funding}

No funding was received for the drafting of the manuscript, nor did any author receive any form of compensation from any public institution or private company for participating in this project.

\section{Authors' Contributions}

Study concepts: Atsushi Naito; Study design: Atsushi Naito; Data acquisition: Atsushi Naito; Quality control of data and algorithms: Yoshinori Kagawa; Data analysis and interpretation: Atsushi Naito;
Table III. Univariate analysis for prognostic variables correlated with 3-year overall survival.

\begin{tabular}{|c|c|c|c|}
\hline & $\begin{array}{l}\text { Number of } \\
\text { cases }\end{array}$ & OS (\%) & p-Value \\
\hline \multicolumn{4}{|l|}{ Age (y) } \\
\hline$\geq 65$ & 10 & 90.0 & \multirow[t]{2}{*}{0.2899} \\
\hline$<65$ & 13 & 71.6 & \\
\hline \multicolumn{4}{|l|}{ Gender } \\
\hline Male & 8 & 71.4 & \multirow[t]{2}{*}{0.6082} \\
\hline Female & 15 & 84.4 & \\
\hline \multicolumn{4}{|l|}{ Tumour location } \\
\hline Right-sided colon (C/A/T) & 5 & 80.0 & \multirow[t]{2}{*}{0.2285} \\
\hline Left-sided colon $(\mathrm{D} / \mathrm{S} / \mathrm{R})$ & 18 & 81.2 & \\
\hline \multicolumn{4}{|l|}{ Timing of resection } \\
\hline Simultaneous & 11 & 77.1 & \multirow[t]{2}{*}{0.7035} \\
\hline Recurrent & 12 & 81.8 & \\
\hline \multicolumn{4}{|l|}{ Histological type } \\
\hline Dif & 19 & 88.2 & \multirow{2}{*}{0.0799} \\
\hline Undif & 4 & 50.0 & \\
\hline \multicolumn{4}{|l|}{ CEA } \\
\hline Positive & 15 & 76.2 & \multirow[t]{2}{*}{0.3655} \\
\hline Negative & 8 & 85.8 & \\
\hline \multicolumn{4}{|l|}{ CA19-9 } \\
\hline Positive & 4 & 75.0 & \multirow[t]{2}{*}{0.5331} \\
\hline Negative & 19 & 80.0 & \\
\hline \multicolumn{4}{|l|}{ M status } \\
\hline M1a/M1b & $11(10 / 1)$ & 80.0 & \multirow[t]{2}{*}{0.5328} \\
\hline M1c & 12 & 79.6 & \\
\hline \multicolumn{4}{|l|}{$\begin{array}{l}\text { Chemotherapy before } \\
\text { metastasectomy }\end{array}$} \\
\hline Yes & 7 & 100 & \multirow[t]{2}{*}{0.7892} \\
\hline No & 16 & 73.1 & \\
\hline
\end{tabular}

Dif: Well or moderately differentiated tubular adenocarcinoma; Undif: mucinous or poorly differentiated adenocarcinoma.

Data analysis and interpretation: Atsushi Naito; Statistical analysis: Atsushi Natio; Manuscript preparation: Atsushi Ntito; Manuscript editing: Kohei Murata; Manuscript review: K. Kawai, A. Takeno, Y. Takeda, M. Otsuka, Y.Suzuki, M. Imasato, Y.FUjie, H. Nakaba, H. Akamatsu.

\section{Acknowledgements}

The Authors gratefully acknowledge the work of past and present members of our hospital.

\section{References}

1 Watanabe T, Muro K, Ajioka Y, Hashiguchi Y, Ito Y, Saito Y, Hamaguchi T, Ishida H, Ishiguro M, Ishihara S, Kanemitsu Y, Kawano H, Kinugasa Y, Kokudo N, Murofushi K, Nakajima T, Oka S, Sakai Y, Tsuji A, Uehara K, Ueno H, Yamazaki K, Yoshida M, Yoshino T, Boku N, Fujimori T, Itabashi M, Koinuma N, Morita T, Nishimura G, Sakata Y, Shimada Y, Takahashi K, Tanaka S, Tsuruta O, Yamaguchi T, Yamaguchi N, Tanaka T, Kotake K and Sugihara K: Japanese Society for Cancer of the Colon and Rectum (JSCCR) guidelines 2016 for 
the treatment of colorectal cancer. Int J Clin Oncol 23: 1-34, 2018. PMID: 28349281. DOI: 10.1007/s10147-017-1101-6

2 Martin LW and Warren RS: Current management of colorectal liver metastases. Surg Oncol Clin N Am 9: 853-876; discussion 877-8, 2000. PMID: 11008255.

3 Kato T, Yasui K, Hirai T, Kanemitsu Y, Mori T, Sugihara K, Mochizuki $\mathrm{H}$ and Yamamoto J: Therapeutic results for hepatic metastasis of colorectal cancer with special reference to effectiveness of hepatectomy: analysis of prognostic factors for 763 cases recorded at 18 institutions. Dis Colon Rectum 46: S22-31, 2003. PMID: 14530655. DOI: 10.1097/01.DCR.000008 9106.71914.00

4 Sudo M, Furuya S, Shimizu H, Nakata Y, Iino H, Shiraishi K, Akaike H, Hosomura N, Kawaguchi Y, Amemiya H, Kawaida $\mathrm{H}$, Inoue S, Kono H and Ichikawa D: Long-term outcomes after surgical resection in patients with stage IV colorectal cancer: a retrospective study of 129 patients at a single institution. World J Surg Oncol 17: 56, 2019. PMID: 30904026. DOI: 10.1186/ s12957-019-1599-3

5 Erroi F, Scarpa M, Angriman I, Cecchetto A, Pasetto L, Mollica E, Bettiol M, Ruffolo C, Polese L, Cillo U and D'Amico DF: Ovarian metastasis from colorectal cancer: prognostic value of radical oophorectomy. J Surg Oncol 96: 113-117, 2007. PMID: 17443728. DOI: $10.1002 /$ jso.20803

6 Huang PP, Weber TK, Mendoza C, Rodriguez-Bigas MA and Petrelli NJ: Long-term survival in patients with ovarian metastases from colorectal carcinoma. Ann Surg Oncol 5: 695698, 1998. PMID: 9869515. DOI: 10.1007/BF02303479

7 Rayson D, Bouttell E, Whiston F and Stitt L: Outcome after ovarian/adnexal metastectomy in metastatic colorectal carcinoma. J Surg Oncol 75: 186-192, 2000. PMID: 11088050.
8 Shida D, Tsukamoto S, Ochiai $\mathrm{H}$ and Kanemitsu Y: Long-term outcomes after R0 resection of synchronous peritoneal metastasis from colorectal cancer without cytoreductive surgery or hyperthermic intraperitoneal chemotherapy. Ann Surg Oncol 25: 173-178, 2018. PMID: 29063295. DOI: 10.1245/s 10434017-6133-7

9 Ahmed S, Leis A, Chandra-Kanthan S, Fields A, Zaidi A, Abbas T, Le D, Reeder B and Pahwa P: Regional lymph nodes status and ratio of metastatic to examined lymph nodes correlate with survival in stage IV colorectal cancer. Ann Surg Oncol 23: 22872294, 2016. PMID: 27016291. DOI: 10.1245/s10434-016-5200-9

10 Stillwell AP, Ho YH and Veitch C: Systematic Review of Prognostic Factors Related to Overall Survival in Patients with Stage IV Colorectal Cancer and Unresectable Metastases. World J Surg 35: 684-692, 2011. PMID: 21181473. DOI: 10.1007/ s00268-010-0891-8

11 Cremolini C, Loupakis F, Antoniotti C, Lupi C, Sensi E, Lonardi S, Mezi S, Tomasello G, Ronzoni M, Zaniboni A, Tonini G, Carlomagno C, Allegrini G, Chiara S, D'Amico M, Granetto C, Cazzaniga M, Boni L, Fontanini G and Falcone A: FOLFOXIRI plus bevacizumab versus FOLFIRI plus bevacizumab as firstline treatment of patients with metastatic colorectal cancer: updated overall survival and molecular subgroup analyses of the open-label, phase 3 TRIBE study. Lancet Oncol 16: 1306-1315, 2015. PMID: 26338525. DOI: 10.1016/S1470-2045(15)00122-9

Received June 28, 2019

Revised July 2, 2019

Accepted July 3, 2019 